\title{
CONDITIONED TASTE AVERSIONS MODIFY NEURAL RESPONSES IN THE RAT NUCLEUS TRACTUS SOLITARIUS ${ }^{1}$
}

\author{
FAT-CHUN TONY CHANG AND THOMAS R. SCOTT ${ }^{2}$
}

Department of Psychology and Institute for Neuroscience, University of Delaware, Newark, Delaware 19711

Received August 5, 1983; Revised December 28, 1983; Accepted January 20, 1984

\begin{abstract}
Explorations of the neural substrates of conditioned taste aversions (CTAs) hve focused principally on diencephalic and telencephalic structures. The nucleus tractus solitarius (NTS) is the initial gustatory relay in the rat's hindbrain. It is worthy of investigation for its part in mediating CTAs in that it is sensitive to several physiological conditions which affect feeding while also being a site of anatomical convergence for vagal afferents from the viscera and centrifugal projections from areas (hypothalamus, amygdala) implicated in emotions and hedonics. We compared single neuron responses from NTS to several taste stimuli in three groups of rats: (1) those receiving exposure to $0.0025 \mathrm{M}$ sodium saccharin without physiological consequences; (2) those made ill through intraperitoneal injections of $\mathrm{LiCl}$ but having no obvious gustatory referent for their malaise (sensitization-pseudoconditioning controls); (3) those in which exposure to $0.0025 \mathrm{M}$ sodium saccharin (the CS) was paired with $\mathrm{LiCl}$-induced poisoning (the US), creating a pronounced aversion to the saccharin. According to response profiles, NTS neurons in all three groups could be divided into subsets of about $30 \%$, which showed a sweet-sensitive profile, and $70 \%$, which were primarily sensitive to nonsweet qualities. The major effect of the conditioning procedure was to increase responsiveness to the saccharin CS only among the sweet-sensitive subset. Moreover, the peak of activity which largely accounted for the increase occurred with a latency of $900 \mathrm{msec}$, perhaps implicating a secondary input to NTS from diencephalic or telencephalic sites. The significance of the results is that: (1) CTAs affect sensory activity at a lower order level than had heretofore been demonstrated; (2) NTS shows sensitivity to yet another physiological condition, reinforcing the involvement of the hindbrain in hedonics and sophisticated taste-related processes; (3) there is a subset of taste neurons, rather distinct according to its sensitivity profile, which is also functionally unique in its response to conditioning by a sweet CS.
\end{abstract}

A wide range of animals show a predisposition to match the gustatory experience of an unfamiliar chemical with the physiological consequences of its ingestion (Garcia and Hankins, 1975). This proclivity permits an especially efficient form of conditioning in which taste preferences or aversions may be established in one gustatory (conditioned stimulus (CS))-visceral (unconditioned stimulus (US)) pairing despite CS-US intervals of several hours. Behaviorally, this unique form of conditioning is most commonly studied through development of conditioned taste aversions (CTAs) where a novel taste is paired with gastrointestinal malaise. The

${ }^{1}$ This work was supported by Research Grants NS 10405 and AM 30964 from the National Institutes of Health and a Biomedical Research Grant from the University of Delaware.

${ }^{2}$ To whom correspondence should be addressed. neural substrates of this process have been studied in scores of experiments, most of which involved ablating selected forebrain structures and testing the ability of subjects to retain former CTAs or to develop subsequent aversions. While these studies have implicated the cortex, amygdala, hippocampus, thalamus, hypothalamus, olfactory bulb, and area postrema as having some involvement in aversion learning, only amygdaloid and hypothalamic participation seems unequivocal.

Acceptance and rejection behaviors are organized in caudal brainstem (Steiner, 1973, 1974; Grill and Norgren, 1978a, b, c; Norgren and Grill, 1982). They are released in stereotypical sequence when an inherently aversive stimulus is tasted or upon encountering a substance to which a CTA has been formed (Gustavson et al., 1974; Grill and Norgren, 1978c). Since hindbrain responses to taste stimuli are known to be influenced by physiological 
state in the rat (Giza and Scott, 1983; Glenn and Erickson, 1976), it is reasonable that the widespread consequences of gastrointestinal distress should modify gustatory neural activity to the presumed cause of the nausea (CS). A likely target of such modulation is the nucleus tractus solitarius (NTS), the initial taste relay in the bulbar brainstem. Here gustatory and visceral afferents converge (Norgren, 1981) but do not directly overlap, communicating instead via the adjacent reticular formation (Hermann and Rogers, 1982). Moreover the neighboring area postrema, with which NTS also communicates, must be intact for the development of certain conditioned aversions to proceed (Berger et al., 1973; Ritter et al., 1980; Rabin et al., 1983). It is this close anatomical relationship with areas sensitive to the internal condition which has caused researchers to suspect NTS involvement in taste aversion learning (Garcia and Ervin, 1968), a suspicion heightened by the increasingly sophisticated role being attributed to the hindbrain in gustatory processing (Scott, 1974; Pfaffmann, 1978; Scott and Perrotto, 1980; Norgren and Grill, 1982). No direct test of this issue has been conducted.

Indirect evidence is equivocal regarding the involvement of NTS in taste aversion learning. Grill and Norgren (1978c; Norgren and Grill, 1982) were unable to induce CT $\Lambda \mathrm{s}$ in decercbrate rats despite a dozen CS-US pairings. While this result justifies the conclusion that the caudal brainstem does not possess complete associative mechanisms necessary for long-term conditioning, it does not preclude either the possibility that NTS would be affected by a C'IA if its input from rostral areas were intact or that it is affected but unable to modify behavior without access to rostral structures concerned with hedonics. Indeed, in an analogous study, decerebrate rats also showed no tendency to adjust salt preferences to compensate for sodium depletion (H. J. Grill, personal communication), despite the well established effects of such a condition on peripheral gustatory activity (Contreras, 1977; Contreras and Frank, 1979). Secondly, Aleksanyan et al. (1976) found that formation of a CTA did not alter the percentage of neurons responding to the CS at the thalamic taste relay and so assumed that hindbrain input to the thalamus, including that from NTS, must also be unresponsive to the aversion. In contrast, however, Loullis et al. (1978) reported a significant disruption of CTA learning when the thalamic taste relay was lesioned. There has been no reconciliation of these contradictory findings.

In the present experiment we directly tested the effects of conditioned taste aversions on the responses of single neurons in the NTS of rats. We performed a large number of comparisons among the responses recorded from unconditioned, pseudoconditioned, and conditioned subjects, so that we might explicitly state which characteristics were and which were not affected by the conditioning procedure. Stimuli included not only the CS but also a range of chemicals unassociated with malaise. Thus, we could evaluate changes in response to a very salient stimulus (CS) as well as alterations in the entire system resulting from the development of a conditioned taste aversion.

\section{Materials and Methods}

Subjects. Subjects were 36 female Wistar rats weighing 250 to $350 \mathrm{gm}$. They were divided into three equal groups: (1) CS only (control); (2) US only; and (3) CS-US pairing (CTA).

Conditioning Procedure. Rats under 20-hr fluid deprivation were trained to lick distilled water from a spout for $15 \mathrm{~min} /$ day. Three hours after each training session they were given access to water for 1 additional $\mathrm{hr}$ to ensure adequate hydration. On the first conditioning day, control and CTA animals were offered $0.0025 \mathrm{M}$ sodium saccharin (NaSac), a novel taste stimulus that served as the CS. Rats in the US group continued to receive water. Immediately after the drinking period animals were injected intraperitoneally with either physiological saline (controls) or $130 \mathrm{mg} / \mathrm{kg}$ of $\mathrm{LiCl}$, the unconditioned stimulus (US and CTA subjects). Lethargy and diarrhea confirmed the resultant gastrointestinal distress in the latter two groups. This procedure was repeated three times on alternate days. The robustness of the aversion was apparent in subsequent drinking tests: CTA rats suppressed CS consumption by $99.4 \pm 0.4 \%$ while controls showed a $7.5 \pm 4.2 \%$ facilitation. Water consumption in the US group was unaffected. It is possible that a pseudoconditioned response could persist throughout the 3-day period between training and recording, particularly in reaction to this noxious experience. Thus, it is important that the US group experienced a corresponding degree of gastrointestinal distress and so could serve to control for this effect. All subjects were behaviorally normal by the time surgery was performed.

Stimuli. For a neuron to be included in this study its responses to seven main stimuli had to be recorded. Four of the seven were prototypes of the putative basic tastes $(0.1$ м NaCl: salty; 0.01 M HCl: sour; 0.5 M sucrose: sweet; $0.005 \mathrm{M}$ quinine $\mathrm{HCl}$ : bitter). The remaining three were the CS $(0.0025 \mathrm{M} \mathrm{NaSac})$, a second NaSac stimulus $(0.25 \mathrm{M}) 2 \mathrm{log}$ units more concentrated, and $0.1 \mathrm{M} \mathrm{LiCl}$. Strong NaSac was included because the taste quality of this solution is concentration-dependent, shifting from predominantly sweet to a complex sweet-bitter-salty sensation at high intensities (Bartoshuk, 1979). It was of interest to determine how much generalization there would be across concentrations of the same molecular species. $\mathrm{LiCl}$ evokes a neural and behavioral response nearly identical to that of $\mathrm{NaCl}$ in rats (Nachman, 1963; Doetsch and Erickson, 1970; Perrotto and Scott, 1976) and so was included to give a relative measure of how typical neural activity was in our preparations.

If the neuron remained well isolated after this series ( 34 of 50 cells were chosen from each group), five other stimuli were applied. These included two more sodium salts, the two monosaccharides of sucrose, and an organic acid. All stimuli and concentrations, plus abbreviations used for each throughout this paper, are listed in Table I.

Surgery. Each rat was anesthetized to a surgical level by ether inhalation. A tracheotomy was performed, and the initial segment of the esophagus was blocked with a short piece of sealed flexible tubing. With both drowning 
TABLE I

Stimuli, molar concentrations, and abbreviations

1. $0.0025 \mathrm{M}$ Sodium saccharin (CS)

2. $0.5 \mathrm{M}$ Sucrose (S)

3. $0.25 \mathrm{M}$ Sodium saccharin (C)

4. $0.1 \mathrm{M} \mathrm{NaCl}(\mathrm{N})$

5. $0.1 \mathrm{M} \mathrm{LiCl}(\mathrm{L})$

6. $0.01 \mathrm{M} \mathrm{HCl}(\mathrm{H})$

7. $0.005 \mathrm{M}$ Quinine $\mathrm{HCl}(\mathrm{Q})$

8. $0.1 \mathrm{M} \mathrm{NaBr}(\mathrm{NB})$

9. $0.1 \mathrm{M} \mathrm{Na}_{2} \mathrm{SO}_{4}$ (NS)

10. $0.01 \mathrm{M}$ Citric acid (CA)

11. $0.5 \mathrm{M}$ Glucose $(\mathrm{G})$

12. 0.5 м Fructose $(\mathrm{F})$

and postingestive effects thus obviated, we could employ the whole mouth stimulus delivery system described below (Chang and Scott, 1984). Still under anesthesia, the animal's occipital bone was exposed, and a $2 \times 5 \mathrm{~mm}$ section was removed to allow access to the nucleus tractus solitarius on either side of the midline. Two skull screws were implanted over parietal cortex for the electrocorticogram recording (ECoG). Incisions for the tracheotomy and in the scalp were closed with wound clips, and all exposed tissue and pressure points were liberally treated with Xylocaine.

Since the conditioning procedure was conducted in the conscious rat, recording should proceed in a similar state. Although conditioned aversions have been developed under anesthesia (Roll and Smith, 1972), considerations of state-dependent learning and alterations in CNS activity by general anesthetics would make recording in this condition a major uncontrolled variable. Thus, when surgery was complete each animal was immobilized with an intraperitoneal injection of Flaxedil (gallamine triethiodide, $60 \mathrm{mg} / \mathrm{kg}),{ }^{3}$ respired using a small animal respirator, and secured in a stereotaxic instrument with blunt, Xylocaine-treated earbars. The necessity of using an immobilized preparation required that extensive precautions be taken to ensure the relative comfort and physiological integrity of the rat. To this end, vital signs were monitored and distress signals (pupillary dilation, blood pressure changes) were attended to continuously throughout a recording session. Temperature was taken rectally and maintained at 36 to $38^{\circ} \mathrm{C}$. Heart rate was recorded through subcutaneous electrocardiographic electrodes and was held at an interbeat interval of approximately $180 \mathrm{msec}$ by adjusting respiration, level of paralysis, and local anesthesia. Expired air was continuously monitored for $\mathrm{CO}_{2}$ content (Instrumentation Laboratory, IL200 $\mathrm{CO}_{2}$ Monitor), which was maintained at 3.0 to $3.8 \%$. The ECoG was continuously monitored. While the preponderance of the record showed desynchrony, slow waves occasionally appeared and could be blocked by tail pinch. There was no evidence of continuous synchrony of the sort reported in Flaxedilized cats (Hodes, 1963).

\footnotetext{
${ }^{3}$ Although cholinergics, including gallamine, may augment activity in peripheral taste nerves (Outwater and Oakley, 1981), our identical treatment of all animals in this regard should permit valid comparisons among the groups.
}

Stimulus delivery. 'The traditional stimulus delivery system for gustatory neural recordings utilizes a flow chamber into which the anterior tongue is gently aspirated. The relatively large volume required to contain the tongue demands that stimulus flow rates be at least several milliliters per second, far beyond the range that the rat would encounter during licking. The three major disadvantages of this system-stimulation of only the anterior tongue, tonic distension of the tongue and jaw, and abnormal flow rates-make it questionable whether a conditioned effect learned through active licking with stimulation of the entire taste system would be fully appreciated during recording.

To relieve some of these unnatural conditions, we stimulated the taste system through a length of slender tubing, closed at the end and extensively perforated along its final $2 \mathrm{~cm}$. The perforated end was slipped into the mouth, held just slightly agape, such that tastants, delivered under mild pressure from a $5-\mathrm{ml}$ syringe, could irrigate nearly the entire oral cavity. ${ }^{4}$ With the esophagus and trachea blocked and the head tilted slightly downward, solutions flowed passively from the mouth into a collecting funnel. Five milliliters of solution were delivered in about 5 sec by this means. The stimulus was then cleared from the tubing by air pressure, and within 10 sec a $25-\mathrm{ml}$ distilled water rinse was initiated. Ninety seconds were allowed to elapse between stimuli to avoid the effects of adaptation.

Unlike the flow chamber method, contact was broken between the fluid and animal after each application. Thus, stimulus-onset time could be marked simply and with precision by determining when that contact was reestablished. This was done with a high input impedance CMOS logic circuit (CD4001 NOR gate). The 11-nA current sustained through the rat upon stimulus contact is far below the threshold for electric taste (Bujas, 1971; Pfaffmann and Pritchard, 1980) and caused no electrical artifacts.

Recording. With the stereotaxic bite bar positioned 1.8 $\mathrm{mm}$ below the interaural line, typical NTS coordinates were $11.3 \mathrm{~mm}$ posterior to bregma, $1.7 \mathrm{~mm}$ lateral to the midline, and $7.5 \mathrm{~mm}$ from the cortical surface. Single neurons were isolated by micropipettes $(Z=5$ to 10 megohms), and potentials were amplified, filtered, displayed, and stored according to conventional techniques.

In a given preparation, neurons were isolated alternately from contralateral solitary nuclei. There was a rostrocaudal progression in $50-\mu \mathrm{m}$ steps with each successive penetration to ensure sampling from the entire NTS. Although robust responses to taste stimuli provide a firm indication of electrode placement, electrolytic lesions were made in the final recording sites of four representative animals ( $20 \mu \mathrm{A}$ for $20 \mathrm{sec}$, electrode negative). Rats were administered a lethal dose of sodium pentobarbital and perfused with $10 \%$ formalin. Brains

\footnotetext{
${ }^{4}$ Dye injections through the stimulus system indicated that the stimulus consistently contacted fungiform, foliate, and circumvallate papillae plus taste buds on the nasoincisor ducts, the Geschmacksstreifen, and most of the posterior palatine field. Only buds on the epiglottis, estimated to represent $4 \%$ of a rat's total (Miller and Spangler, 1982), were not regularly contacted.
} 

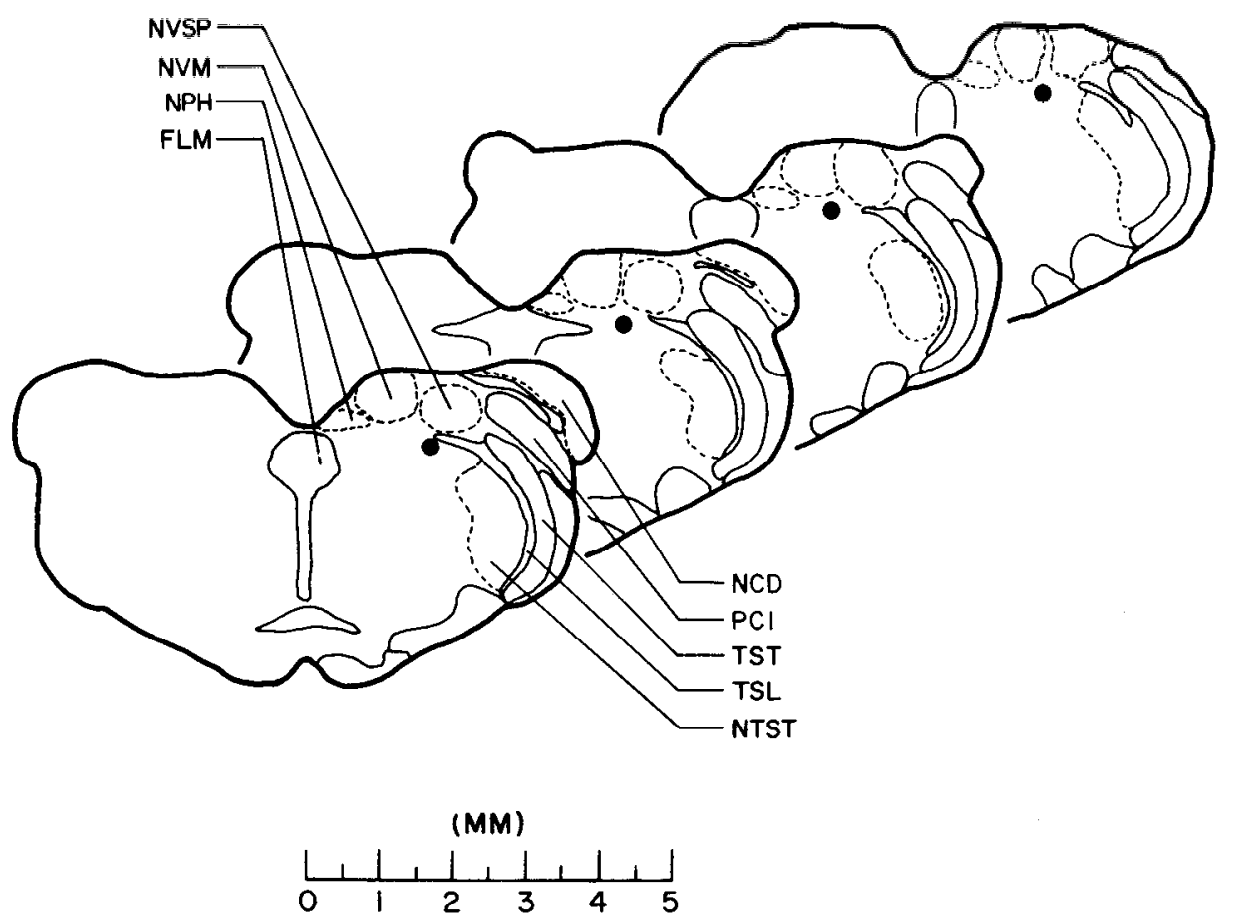

Figure 1. Histological drawings showing the locations of marking lesions in four preparations, made at successive rostrocaudal levels of NTS. FLM, medial longitudinal fasciculus; $N C D$, dorsal cochlear nucleus; $N P H$, prepositus nucleus; $N T S T$, spinal nucleus of the trigeminal nerve; $N V M$, medial vestibular nucleus; $N V S P$, spinal vestibular nucleus; $P C I$, inferior cerebellar peduncle; $T S L$, solitary tract; $T S T$, spinal tract of the trigeminal nerve. (From Pellegrino et al., 1979; used with permission from Plenum Press.)

were removed, blocked, and cut in $50-\mu \mathrm{m}$ frozen sections to identify lesion sites (Fig. 1).

Analyses. The neural responses of each group were compared for general characteristics and spatial and temporal distribution of activity. The response criterion was a change in neural activity of $1.28 \mathrm{SD}$ from the mean spontaneous activity for that cell, sustained for $3 \mathrm{sec}$. Basic calculations (spontaneous and evoked discharge rates, time histograms) were done on a PDP 11/03 computer; derived analyses (interneuronal correlations, cluster analyses) were performed on a B7700. All graphics except histology were controlled by a DEC-10 and plotted by an HP7221A.

\section{Results}

The major effect of the conditioning procedure was to increase responsiveness to the saccharin CS among that $30 \%$ of the neurons which showed particular sensitivity to the sweet quality. In addition, the peak of activity which accounted for this increase did not occur until 900 msec after stimulus onset.

Discharge rates. We first sought to determine whether overall discharge rates were affected by the conditioning procedure. Figure 2 presents mean spike rates across the entire neural sample in each of the three groups. The only significant effect is a decrease in response to citric acid among US group cells ( $p<0.05$, Tukey test). However there is a tendency toward increased responsiveness to the saccharin CS among CTA neurons. This may indicate merely an insignificant tendency or a more

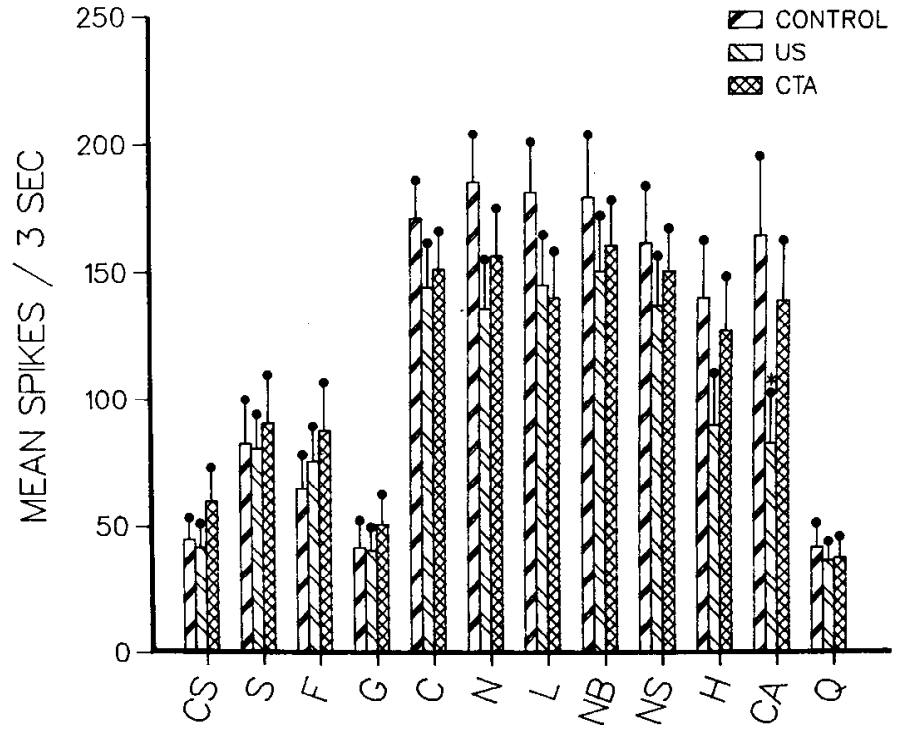

Figure 2. Mean discharge rates across the entire neural sample. $N=50$ for each bar representing the seven main stimuli, and $N=34$ for the remaining five chemicals. Stimuli are grouped by quality (four "sweets," $0.25 \mathrm{M} \mathrm{NaSac}$, four NaLi salts, two acids, quinine) to demonstrate that within each, the relative responses across groups are quite consistent. The asterisk on citric acid indicates $p<0.05$.

powerful effect which is diluted by averaging across the entire neural sample. Thus, it becomes important to inspect the responses of individual cells. In Figure 3, the 50 neurons of each group are ranked according to their 
A: .0025M NASAC (CS)

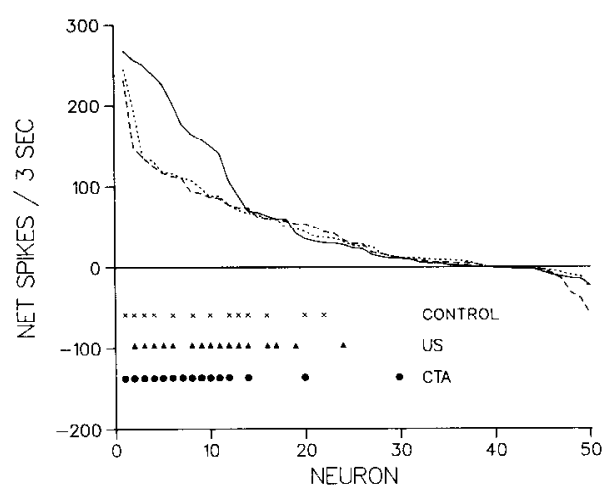

B: SUCROSE

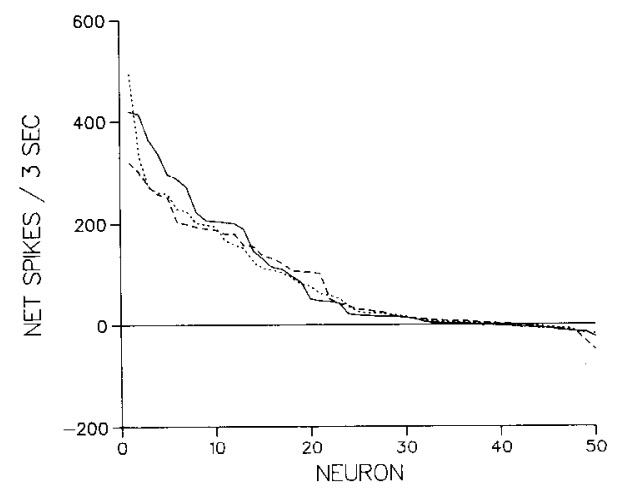

C: .25M NASAC

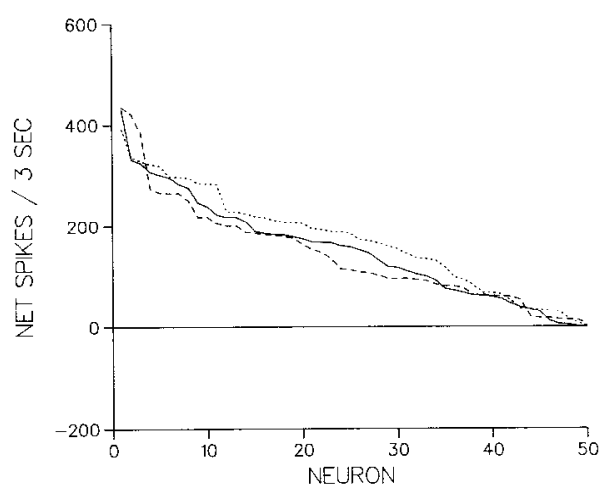

D: NACL

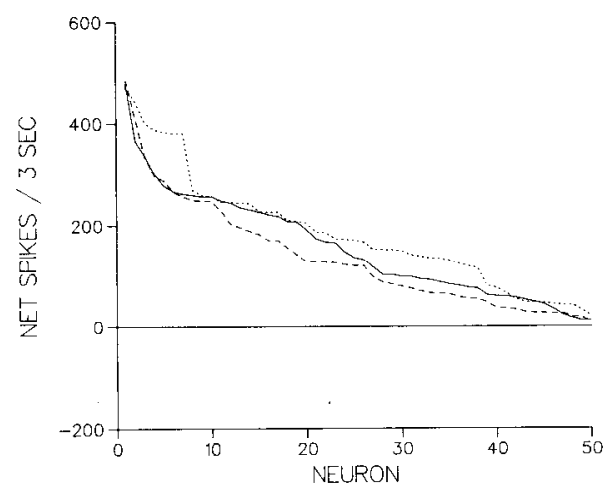

E: $L I C L$

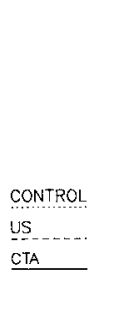

F: HCL

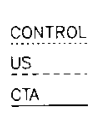

CONTROL
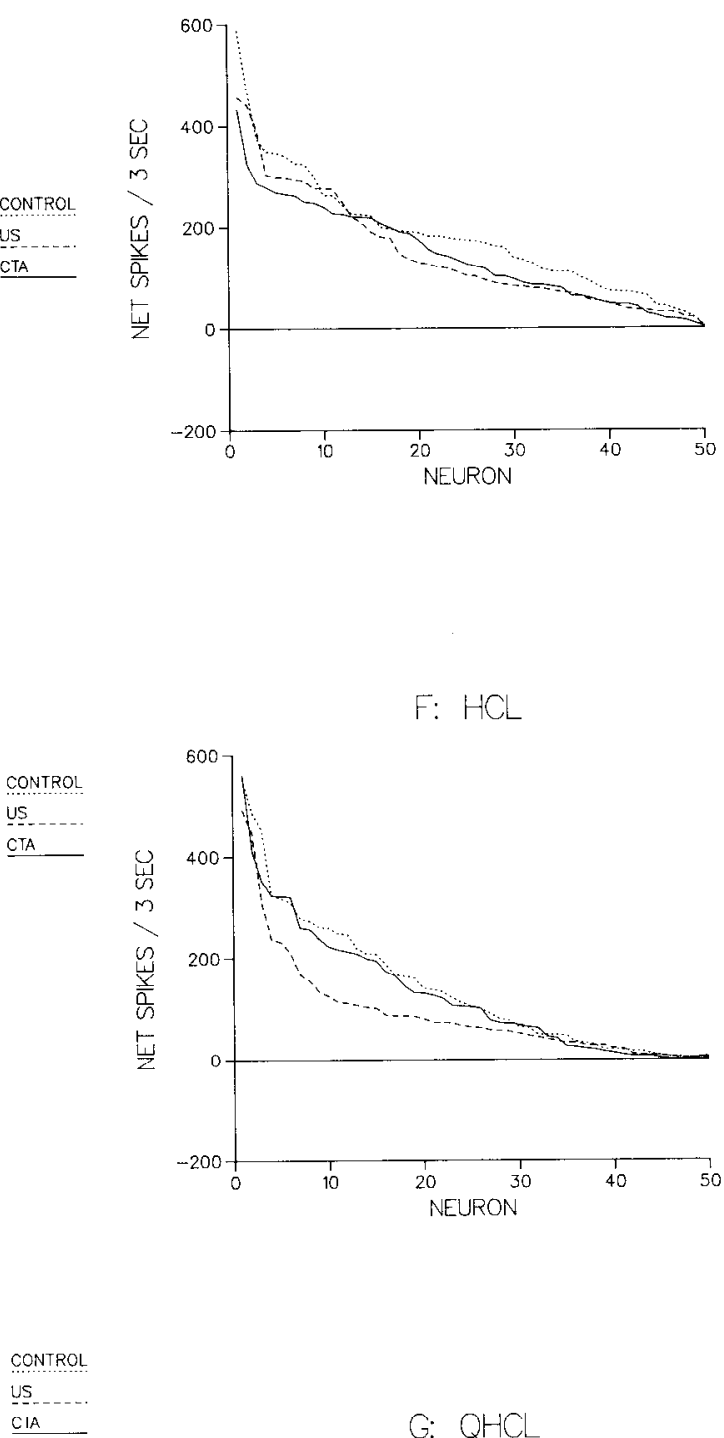

CONTROL

US ....

CTA

CTA

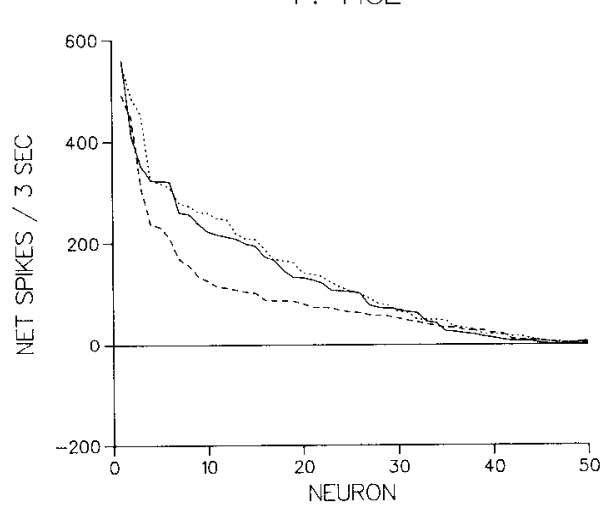

CONTROL

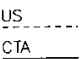

G: $Q H C L$

CONTROL

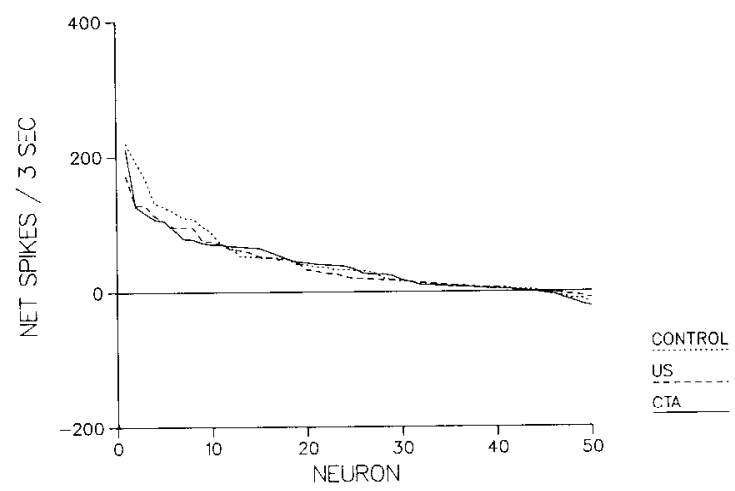

Figure 3. Responses of individual cells to each of the seven main stimuli. Neurons are ordered on each graph according to their discharge rates to that chemical. In $A$, neurons with sweet-sensitive profiles (see below) are indicated by symbols near the abscissa. A, $0.0025 \mathrm{M} \mathrm{NaSac}(\mathrm{CS}) ; B$, sucrose; $C, 0.25 \mathrm{M} \mathrm{NaSac} ; D, \mathrm{NaCl} ; E, \mathrm{LiCl} ; F, \mathrm{HCl} ; G$, QHCl. 
responsiveness to each of the seven main stimuli. For the saccharin CS (Fig. $3 A$ ), there is an increase in activity among CTA neurons which is restricted to the 13 cells giving the largest saccharin responses. Of the other six main stimuli (Fig. 3, $B$ to $G$ ), only the decrease to acid among US cells is apparent (Fig. $3 F$ ).

We must now ask whether these neurons, which were apparently responsive to the conditioning procedure, represent a distinct subpopulation of gustatory cells. While an individual taste neuron is broadly tuned, its response to any one stimulus permits predictions of how it will respond to all other chemicals. For example, discharge rates of six cells which were most receptive to $\mathrm{HCl}$ in the control group are plotted in Figure 4. Here, a robust response to $\mathrm{HCl}$ (by definition) implies moderate-strong activation by $\mathrm{Na}-\mathrm{Li}$ salts, moderate responses to $0.25 \mathrm{M}$ $\mathrm{NaSac}$, and only weak activity to sucrose, $\mathrm{QHCl}$, and $0.0025 \mathrm{M} \mathrm{NaSac}$ (CS). A quantitative expression of this recurrent pattern is available through the Pearson product-moment correlation coefficient (Erickson, 1963), the mean for which among the response profiles of these six HCl-best fibers is $+0.89(N=15)$. Thus, a predictable pattern from a specified cell-a neuron type-is suspected. A more comprehensive analysis of the presence of neuron types comes from the full correlation matrix among all 50 cells in each group (1250 correlations per group). Such a matrix provides the basis for performing a cluster analysis (Wishart, 1978) in which neurons are placed in proximity to one another according to the similarity of their response profiles across the stimulus array. Figure 5 depicts dendrograms which indicate some tendency toward clustering (i.e., toward the presence of gustatory neuron types) in each of the three groups of this study. Neurons are numbered in the order in which they were recorded, and they are interconnected by horizontal lines at the correlation level between their response profiles. Where groups of neurons are connected, the height of the connecting horizontal line is set at the mean intercorrelation between the two groups. Beneath each cell is indicated the stimulus which evoked its largest response followed by any other chemical which was $>85 \%$ as effective. ${ }^{5}$ In each dendrogram there is a

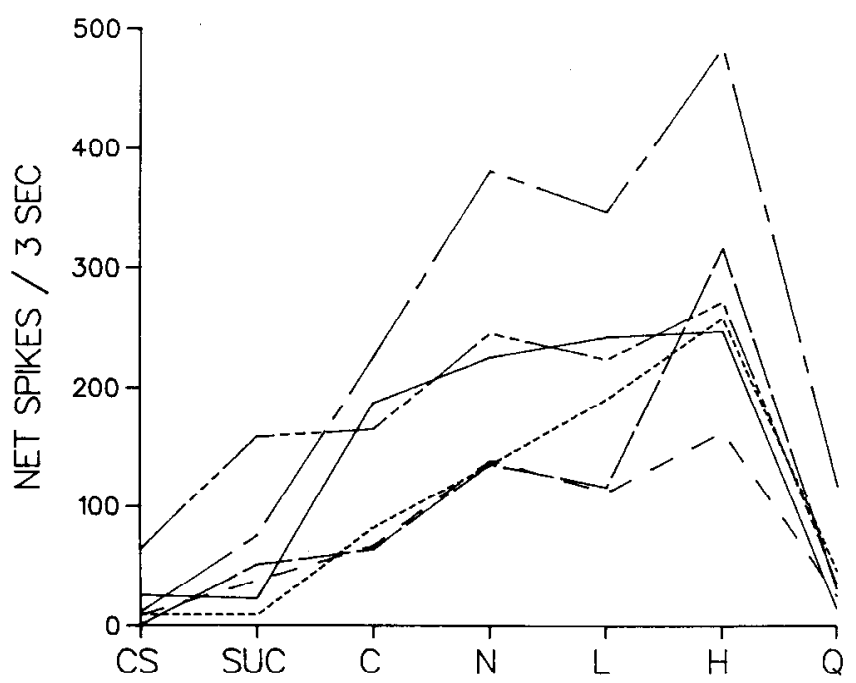

Figure 4. Response profiles of the six HCl-best neurons from the control group. basic division between neurons toward the right side, which show a pattern of sensitivity to sweet stimuli $(N$ $=13$ in the control group, 16 in the US-cells 31 and 33 not included-and 15 in the CTA), and the remainder, among which further subdivision may be possible, although this is not relevant to the topic of this paper. Neurons that compose the sweet-sensitive populations in each experimental group are identified by symbols along the abscissa in Figure 3A. The agreement between these two approaches to segregating a neural subgroupone based on a sensitivity profile, the other on the effects of conditioning-should be high. Robust responses to sweets would both largely define the neuron's sensitivities and imply particular susceptibility to effects that may result from the use of a sweet CS. In fact, the overlap is nearly total. Thus, our results indicate that there is a subset of neurons, rather distinct according to its sensitivity profiles, which is also functionally unique in its response to conditioning by a sweet CS. Based on this discharge rate analysis, any change in the neural representation of $0.0025 \mathrm{M} \mathrm{NaSac}$, resulting from its role as the $\mathrm{CS}$ in a conditioned aversion paradigm, is mediated almost exclusively through a sweet-sensitive subgroup of neurons.

Figure 6 presents discharge rates to the seven main stimuli for only those neurons which composed the sweet-sensitive subgroup in each experimental condition. The increase to the saccharin CS among CTA group cells is significant $(p<0.01$, Tukey test).

Time course. We plotted post-stimulus time histograms (PSTHs) to determine whether the increases described above were temporally uniform or whether they revealed an altered character of the response. Figure 7 shows the PSTHs of the saccharin CS and, for comparison, that of $0.25 \mathrm{M} \mathrm{NaSac}$, to which we detected no electrophysiological generalization of the conditioning effects. When all 50 neurons are included in the analysis, the PSTH to $0.25 \mathrm{M} \mathrm{NaSac}$ (Fig. $7 \mathrm{~A}$ ) is essentially unmodified by the conditioning procedure. In contrast, the increased response to the saccharin CS (Fig. $7 b$ ) is revealed to be in a delayed component having a latency to peak of $900 \mathrm{msec}$. When the sweet-sensitive subgroup is isolated for analysis, this effect becomes striking. PSTHs among the three experimental groups still show no differences to $0.25 \mathrm{M} \mathrm{NaSac}$ (Fig. $7 \mathrm{C}$ ); however, in response to the saccharin CS, there is an obvious burst of activity, peaking at $900 \mathrm{msec}$, among sweet-sensitive CTA neurons (Fig. $7 D$ ). This reaffirms the crucial role played by this subgroup in mediating the effect and isolates the most apparent consequence of a conditioned aversion in NTS to one well defined peak of activity.

\footnotetext{
${ }^{5}$ Only the seven main stimuli were considered. Moreover, for simplicity of interpretation, $\mathrm{NaCl}$ and $\mathrm{LiCl}$ were both treated as sodium salts and represented by the letter $N$ in these dendrograms. As an indication of their similarity, the product-moment correlation coefficient between the neural patterns evoked by these two stimuli was +0.98 . Also, neuron 20 of the CTA group, despite its "S" label, responded best to the saccharin CS. The representation of $0.25 \mathrm{M} \mathrm{NaSac}$ (letter $C$ ) in both sweet and nonsweet subgroups highlights the complex character of this stimulus, variously described as salty, sweet, and bitter.
} 

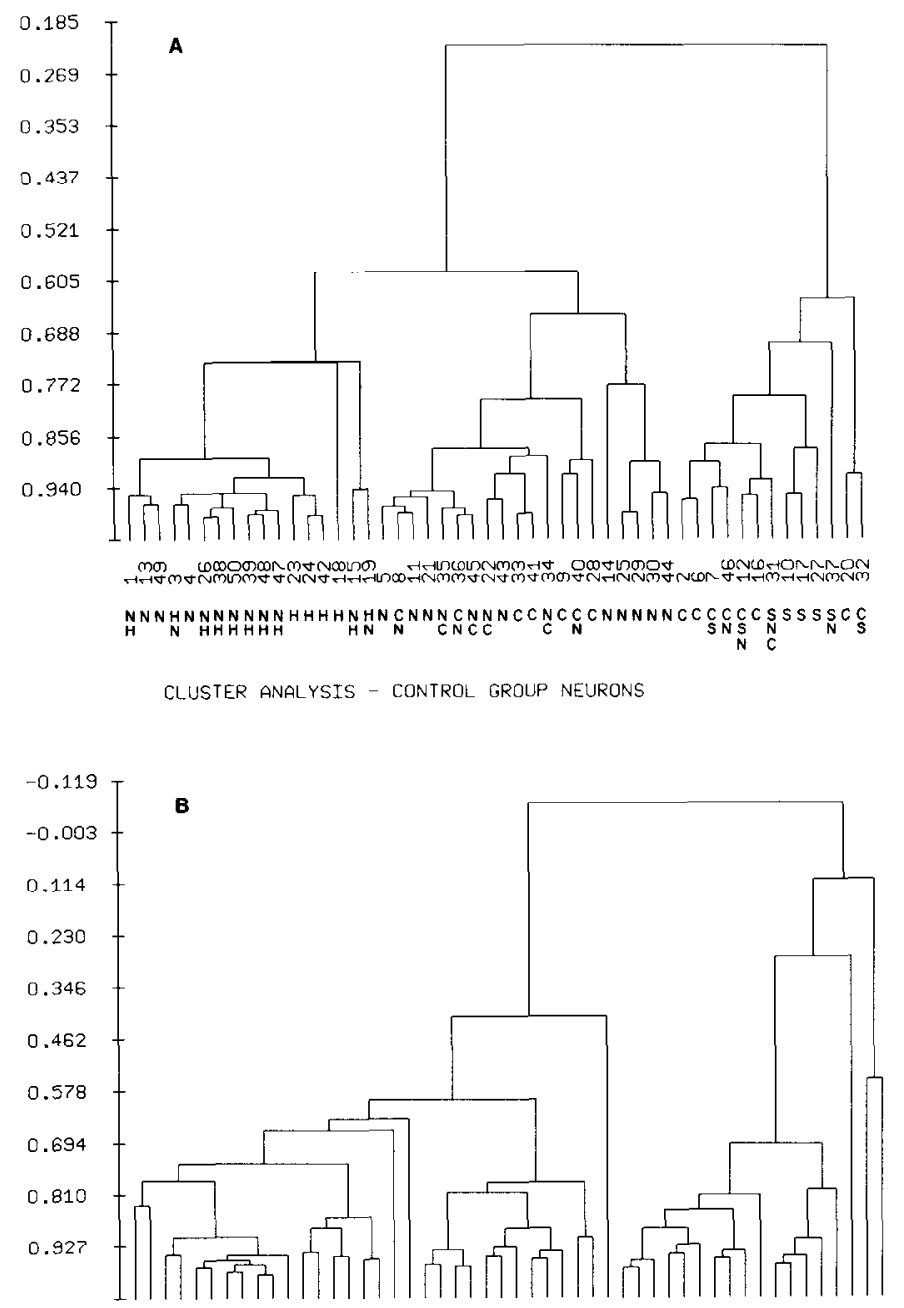

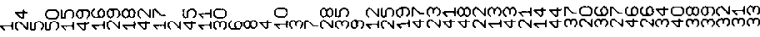

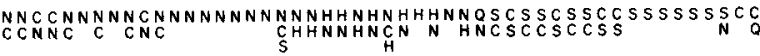

CLUSTER ANALYSIS - US GROUP NEURONS

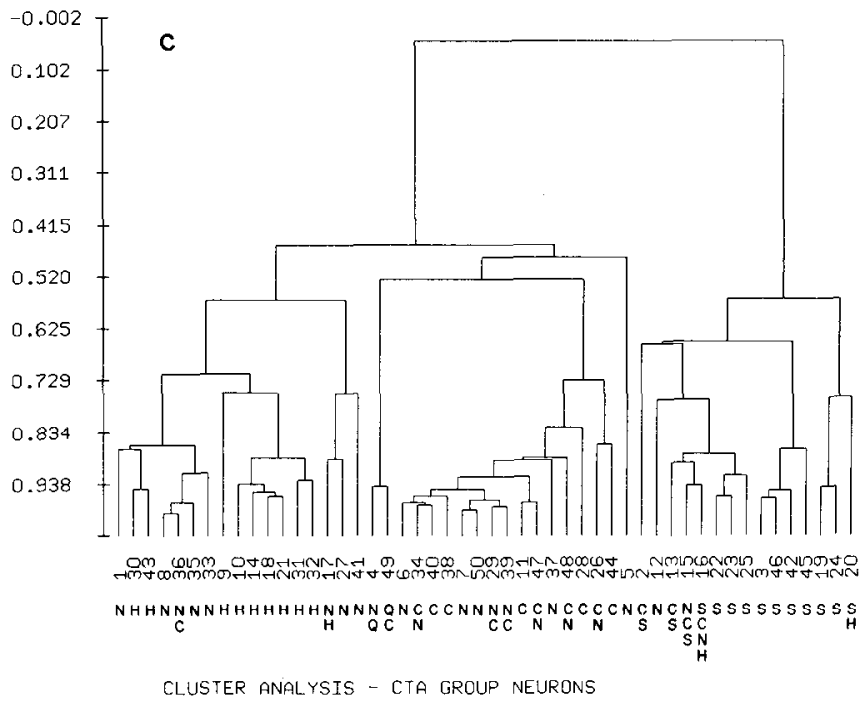

Figure 5. Dendrograms for each group, relating neurons to one another according to the similarities of their response profiles. $A$, Control group; $B$, US group; $C$, CTA group. In each dendrogram there is a basic division between sweet-sensitive (right) and nonsweet-sensitive (left) profiles.

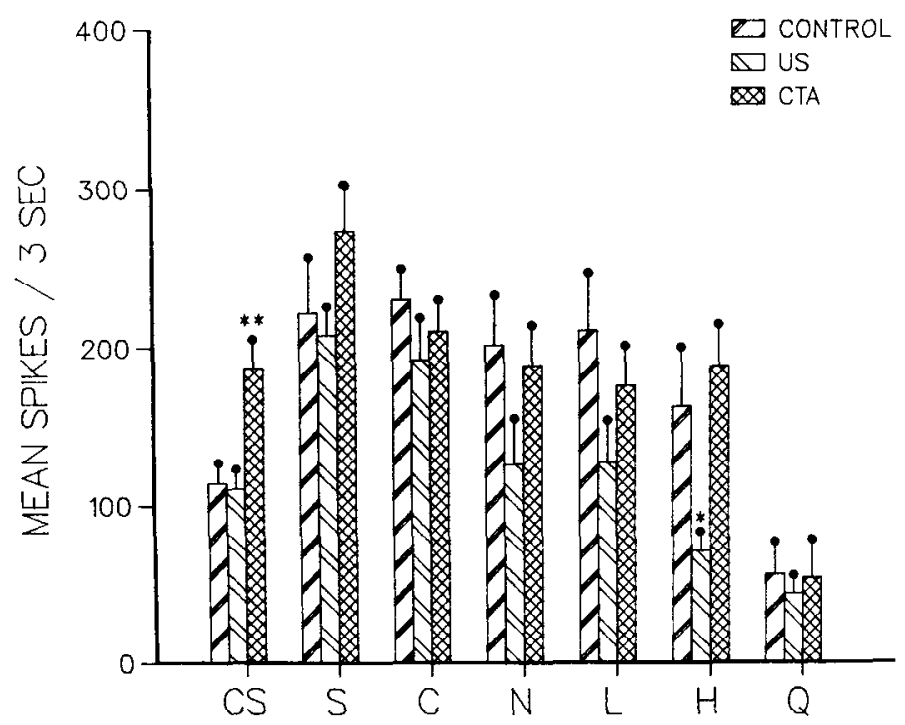

Figure 6. Mean discharge rates across only the sweet-sensitive subgroups. $N=13$ for the control group, 16 for the US group, and 15 for the CTA group. One asterisk indicates $p<$ 0.05 , two asterisks indicate $p<0.01$.

Generalization. Generalization of the neural effects seen here is quite limited. Figure 8 presents PSTHs for sucrose (Fig. $8 A$ ), glucose (Fig. $8 B$ ), and fructose (Fig. $8 C$ ) - those stimuli most qualitatively similar to the saccharin CS-calculated only across the sweet-sensitive neural subgroups. ${ }^{6}$ Each shows some tendency toward an enhanced response among CTA cells, although the result is less pronounced than for the CS. Moreover, the latency of the enhancement is less striking among sugars because the control group PSTH does not peak until the end of the first second, nearly matching the latency to peak of the PSTH in CTA rats. As noted, there is no apparent generalization to $0.25 \mathrm{M} \mathrm{NaSac}$, nor is there to any of the seven other main and secondary stimuli representing salty, sour, and bitter qualities. A behavioral comparison would be most informative, but we know of no studies which have developed CTA generalization gradients around a weak saccharin solution.

Other effects. The bar graphs of Figures 2 and 6 and the rank order graph of Figure $3 F$ all indicate a significant suppression of acid responsiveness in the US group. In contrast to the specificity of the saccharin CS effect among CTA neurons, the acid reduction is broad. A mean of $72 \%$ of the cells ( 36 of 50 ) responded to $\mathrm{HCl}$ in the three groups; in these, the weakest response was from the US group in every case but one (see $\mathrm{HCl}$, Fig. $3 F$ ). For citric acid (a secondary stimulus) a mean of $76 \%$ (26 of 34) of the cells met our response criterion, and the smallest response came from the US group each time. The proper interpretation of this finding remains elusive.

${ }^{6}$ Glucose and fructose were secondary stimuli to which the responses of only 34 neurons were recorded in each group. Cluster analyses performed on these three 34-cell samples indicated sweet-sensitive subgroups of 10 in the control condition, 8 in the US, and 11 in the CTA group. It is upon these subgroups that glucose and fructose PSTHs are based. 
A: $.25 \mathrm{M} \mathrm{NASAC}$

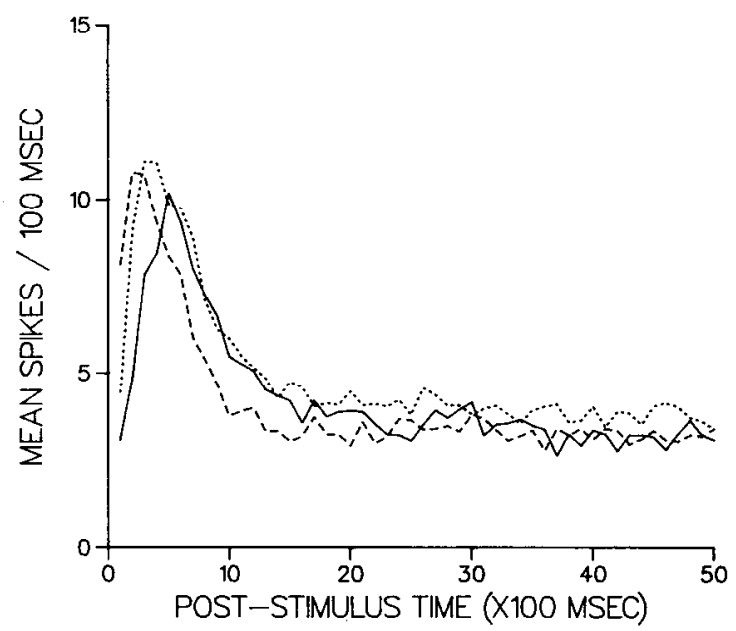

C: .25M NASAC

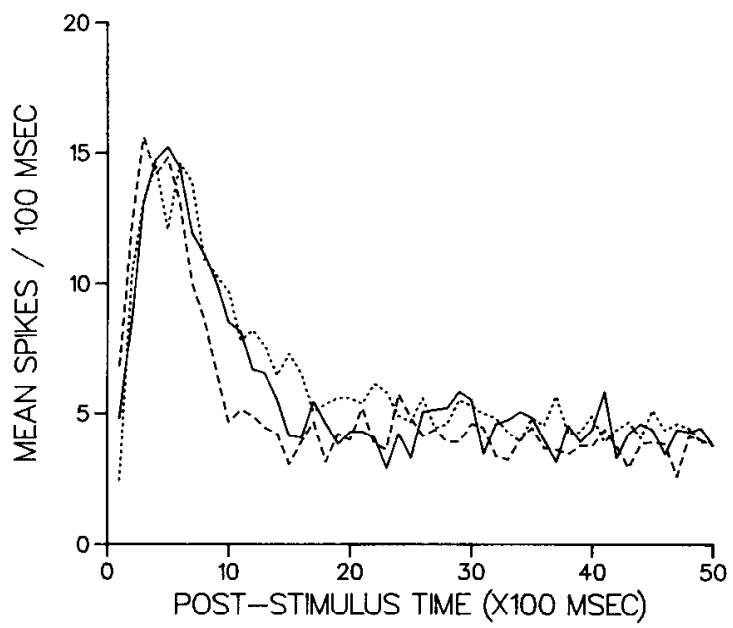

B: .0025M NASAC (CS)
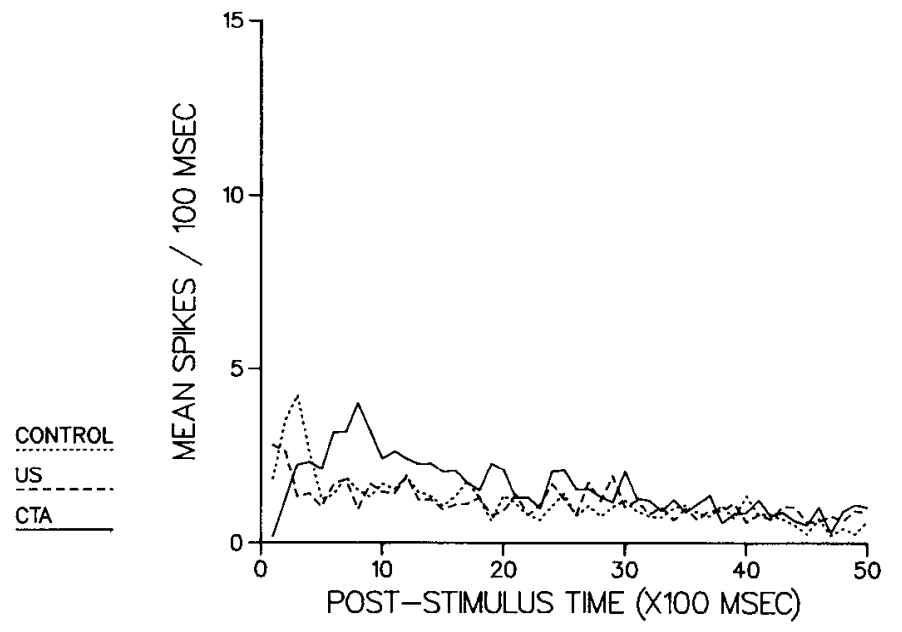

CONTROL US --...

\section{D: .0025M NASAC (CS)}

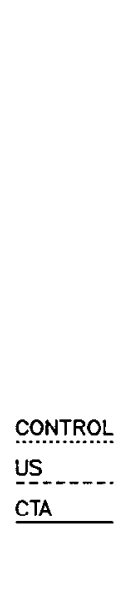

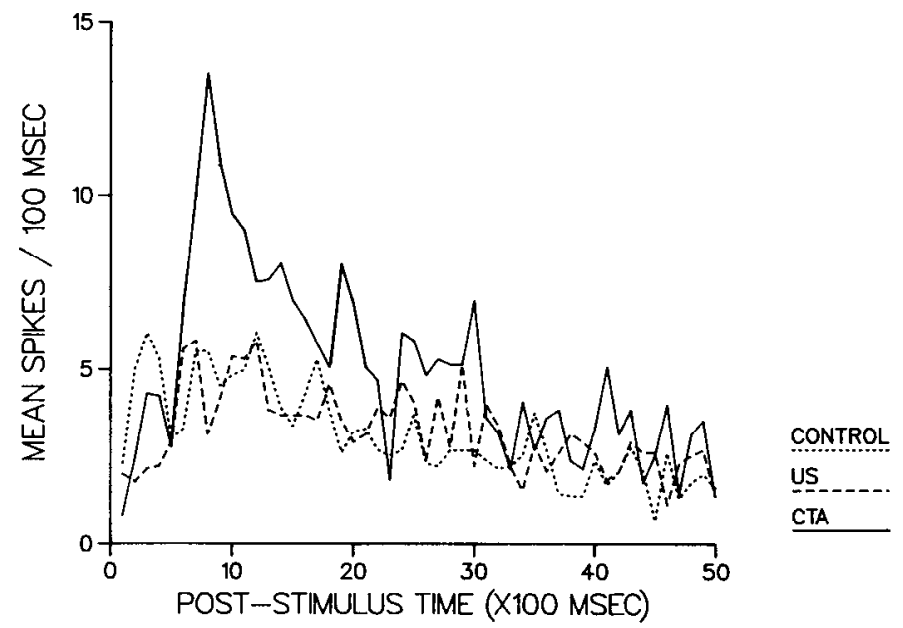

Figure 7. Post-stimulus time histograms to $0.25 \mathrm{M} \mathrm{NaSac}$ and $0.0025 \mathrm{M} \mathrm{NaSac}$ (CS). A, PSTHs to $0.25 \mathrm{M}$ NaSac calculated across all 50 neurons of each group. $B$, PSTHs to $0.0025 \mathrm{~m} \mathrm{NaSac} \mathrm{(CS)} \mathrm{across} \mathrm{all} 50$ neurons. $C$, PSTHs to $0.25 \mathrm{M} \mathrm{NaSac}$ calculated across only the sweet-sensitive subgroups. $D$, PSTHs to $0.0025 \mathrm{M} \mathrm{NaSac}$ (CS) across the sweet-sensitive subgroups.

\section{Discussion}

Conditioning and the gustatory neural code. The most striking result of this study is the development of a distinct long latency response to the CS among the sweetsensitive subgroup of NTS neurons.

This effect of the conditioning procedure should in some way be reflected in the gustatory neural code for the CS (and perhaps other chemicals) and manifested in behavior. Since a range of taste qualities was employed in this experiment, we were in a position to evaluate the general consequences of conditioning on the code for taste. For this analysis we relied on the across-fiber pattern theory of gustatory coding both because rather sophisticated analytical tools have been developed in association with it (Erickson et al., 1965; Guttman, 1968) and because it has permitted strikingly accurate predictions of taste-related behavior (Nachman, 1962, 1963; Erickson, 1963; Morrison, 1967).

In Figure 4, the profile of each $\mathrm{HCl}$-best neuron was determined by reading that cell's activity across stimuli.
Neural profiles were then compared for similarity by means of Pearson's product-moment correlation coefficient. Applying this analysis to all neurons, full correlation matrices were generated for each experimental group, and these served as the basis for the cluster analyses of Figure 5 . In the same way, the response profile for each stimulus can be determined by reading across neurons. The taste quality of a stimulus would be represented by the profile of activity it evoked from the 50 cells which had the opportunity to respond to it. Twelve such profiles would be generated, and correlations between each pair would provide an index of gustatory similarity for that pair. With all pairs intercorrelated (66 correlations per group), their relative similarities may be spatially expressed through multidimensional scaling. This is simply a graphic representation of the correlations, with those stimuli which evoke highly correlated patterns placed near one another and those with disparate patterns spaced widely apart (Guttman, 1968).

The three-dimensional spaces resulting from taste 


\section{A: SUCKOSt}
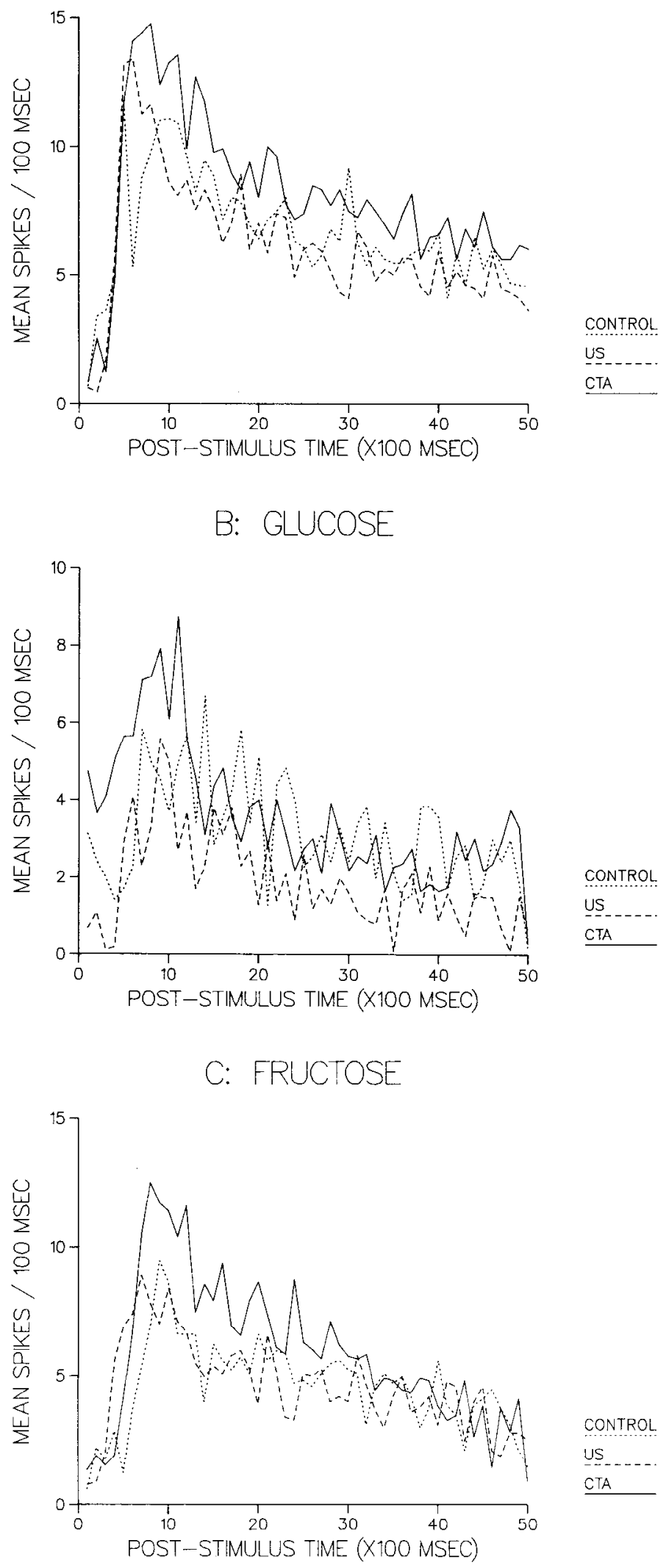

Figure 8. Post-stimulus time histograms for $(A)$ sucrose, $(B)$ glucose, and $(C)$ fructose calculated across only the sweetsensitive subgroups.
CONTROL

US CTA US CTA CiA

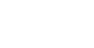
CONTROL quality analyses of the control and CTA groups are shown in Figure 9. The axes of the spaces are unlabeled, for the attributes they represent - which should underlie taste just as frequency underlies pitch and wavelength, color-are not yet determined. The control group (Fig. $9 A$ ), representing the normally functioning taste system, presents a space similar to that seen by others (Doetsch and Erickson, 1970). 'The clear distinction between sweet and nonsweet stimuli is apparent, as is the precise arrangement of individual chemicals within a taste category: the four $\mathrm{Na}-\mathrm{Li}$ salts, by the neural patterns they elicit here, should be virtually undistinguishable. ${ }^{7}$ Concentrated NaSac, possessing a complex taste described by humans as sweet and bitter (Bartoshuk, 1979) and possessing an obvious salty component, is situated between the sweet and nonsweet chemicals. Finally, $\mathrm{QHCl}$, the prototype of bitter, falls at the opposite extreme from the sweet stimuli.

The consequence of a conditioned taste aversion is to disrupt this clear organization (Fig. 9B). The similarity among salts, acids, and quinine diminishes; the sharp distinction between sweet and nonsweet chemicals is reduced. ${ }^{8}$ Moreover, the sweet versus nonsweet gap is closed through differential movement of nonsweet chemicals; salts move rather little, and quinine moves the most. The approach of quinine to the sweet chemicals is so decisive that it is situated nearly as close to the sweet CS as it is to the acids. This is a result which would be quite out of place in a normally functioning gustatory system. It may offer a neural concomitant to the increasingly similar behavioral reaction elicited by quinine and sweet chemicals to which an aversion has been conditioned (Grill and Norgren, 1978a). Common experience suggests that it is the hedonic attribute of the CS, rather than its perceived quality, which is altered by the development of a taste aversion. Therefore, this analysis also implies that the hindbrain gustatory code carries a hedonic component in addition to information regarding stimulus quality and intensity. This implication is in accord with the hypotheses of other investigators (Scott

\footnotetext{
${ }^{7}$ The extremely high correlations among patterns in this tight stimulus cluster $(r=+0.96$ to 0.98 ) indicate not only that the taste qualities are nearly identical (as behavioral tests verify) but also that the data collection process was precise. This validation of the experimental techniques permits greater confidence in the differences shown between experimental groups.

${ }^{8} \mathrm{We}$ inserted three extreme anchor points (not shown) to fix the boundaries of each space. Spaces were then adjusted relative to one another so as to assign NaSac (CS) the same coordinates in each. Therefore, the relative positions of stimuli in the two spaces are directly comparable, but absolute positions are not. There is no way of distinguishing between quinine's moving toward the CS or the converse. This explains why nonsweet stimuli show distinct movement between spaces when they were apparently not affected by the conditioning procedure (Fig. 3, $B$ to $G$ ). While they may not move in absolute terms, these stimuli are probably approached by the CS, whose neural code and, thus, spatial position are modified by the aversion. But with only relative positions defined and with the CS fixed, this movement is attributed to nonsweet chemicals.
} 

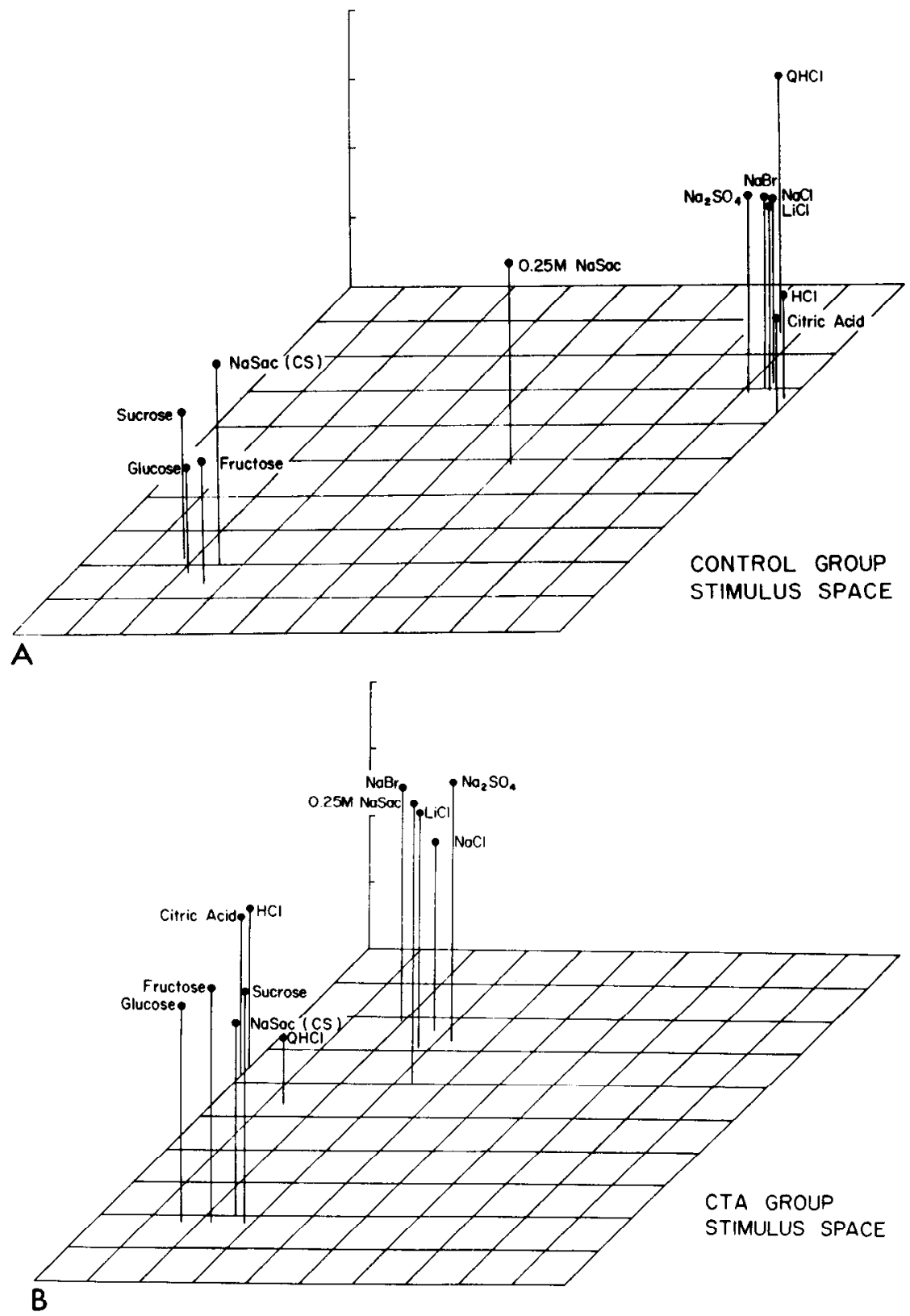

Figure 9. Three-dimensional spaces representing relative similarities among stimuli as determined from neural responses in the control group $(A)$ and the CTA group $(B)$. NaSac (CS) is at the same coordinates in each space.

and Perrotto, 1980; DiLorenzo and Schwartzbaum, 1982), who have proposed that hedonics is a major feature of the hindbrain code for taste.

Mechanisms. There is some suggestion from the literature that enhanced activity to the CS in the conditioned animals may result from a secondary centrifugal influence on NTS from diencephalic and/or telencephalic sites. The 900 -msec latency is sufficient to permit such a circuitous input, although this time course does not exclude any other delayed influence. More specific is the report by Grill and Norgren (1978c) that decerebrate rats lose their capacity to develop and maintain conditioned aversions. Thus, the caudal brainstem, even with its visceral vagal afferents intact, does not possess the full associative mechanisms necessary for a CTA. Areas rostral to the midbrain are required. Among higher order structures which may contribute to the 900 -msec peak, the hypothalamus and amygdala are most likely. First, they are both firmly implicated in the mediation of emotional and hedonic processes which are drastically altered by formation of a CTA. Secondly, lesion experiments are consistent in finding that these areas must be intact for the formation and maintenance of conditioned avcrsions to proceed (McGowan et al., 1972; Kemble and Nagel, 1973; Rolls and Rolls, 1973; Roth et al., 1973; Nachman and Ashe, 1974; Schwartz and Teitelbaum, 
1974; Arthur, 1975; Kesner et al., 1975; Kolb et al., 1977; Mikulka et al., 1977). Finally, both hypothalamus and amygdala receive gustatory afferents (Norgren and Leonard, 1973; Norgren, 1976) and send robust centrifugal projections back to NTS (Saper et al., 1976; Bereiter et al., 1979; Price and Amaral, 1981), providing an established circuitry for our electrophysiological results.

If the long latency peak does not mediate the conditioned response, then rejection of a sweet CS should require at least $700 \mathrm{msec}$, at which time the CTA curve begins to differentiate from those of the controls. Both Halpern and Tapper (1971) and Scott (1974) have demonstrated rejection of CSs in under $600 \mathrm{msec}$; however, these studies use salt and acid stimuli which evoke a sharper phasic peak of taste activity than $0.0025 \mathrm{M}$ $\mathrm{NaSac}$, perhaps expediting the process. In addition, both used trained rats which could anticipate frequent exposure to the CS and which were required to discriminate between it and only one other chemical. A more valid temporal comparison might come from the technique developed by Grill and Norgren (1978a) by which the rejection response to a sweet $\mathrm{CS}$ after aversive conditioning could be analyzed.

Other implications. Contreras and Frank (1979) have studied gustatory neural responses in the chorda tympani nerves of sodium-deprived rats. They report a response suppression to $\mathrm{NaCl}$ only among those fibers whose best response is to sodium salts. Our results are complementary in that we have also developed a specific physiological state which generated changes only in the subgroup of neurons particularly sensitive to the relevant taste quality. Moreover, the direction of the modulation was logically consistent: the Na preference created by Contreras and Frank's protocol resulted in a response decrement to $\mathrm{Na}$ salts; the saccharin aversion created by ours led to a response increase to the saccharin CS. Contreras and Frank's interpretation of the decreased sodium sensitivity in salt-deprived rats is that a higher concentration of sodium will be necessary to drive taste responses through their dynamic range; thus, the salt preference curve will be shifted to higher molarities and the rat will consume more concentrated solutions, restoring salt balance more readily. By extension of this argument, if a greater need to consume a chemical is manifested in decreased sensitivity, a greater need to avoid it-as we created through conditioning - should be reflected in the hypersensitivity we recorded. This inverse relationship between quantity to be consumed and taste sensitivity is crudely maintained through the mammal's gustatory domain. A moderate intensity for quinine is $1 \mathrm{mM}$; for $\mathrm{HCl}, 5 \mathrm{mM}$; for $\mathrm{NaCl}, 50 \mathrm{~mm}$; for sucrose, $500 \mathrm{~mm}$. The results of Contreras and Frank and our study suggest that these dynamic ranges can be modified by physiological need and experience.

The fact that only the most sensitive subgroup of neurons was affected by the sodium deprivation and conditioning procedures implies the existence of selective channels within the taste system which mediate the processing of, or reactions to, certain stimulus categories. However, a "best-stimulus" categorization is not the optimal way to select the neural subgroup unless one is dealing with a very effective stimulus, such as $\mathrm{NaCl}$. By this criterion, only one of our 44 sweet-sensitive neurons (13 in the control group, 16 in US, 15 in CTA) would have qualified as responding best to the saccharin CS. The analysis of a neuron's activity profile would seem more appropriate.

Finally, our findings may reconcile the results of Aleksanyan et al. (1976), showing no change in the proportion of thalamic taste neurons responding to the CS after conditioning, with those of Loullis et al. (1978) which indicate a disruption of CTA acquisition with thalamic lesions. We found no alteration in the number of NTS cells signaling the CS. Aleksanyan et al. based their conclusion of thalamic (and, by implication, NTS) noninvolvement in CTAs upon similar data. But that subgroup of NTS neurons which was particularly sensitive to the CS increased the vigor and altered the temporal character of its activity. If these modifications are retained in the thalamus, their loss through lesioning could explain the conditioning deficit reported by Loullis et al.

Most aspects of feeding beyond explicit quality and intensity determinations of chemicals have classically been attributed to hypothalamus or forebrain limbic areas. Our results, in conjunction with those of studies involving NTS, area postrema, and vagal afferents, imply that the hindbrain is also sensitive to gastrointestinal effects and deals in the hedonic and motivational aspects of feeding.

\section{References}

Aleksanyan, A. A., O. Buresova, and J. Bures (1976) Modification of unit responses to gustatory stimuli by conditioned taste aversion in rats. Physiol. Behav. 17: 173-179.

Arthur, J. B. (1975) Taste aversion learning is impaired by interpolated amygdaloid stimulation but not by post-training amygdaloid stimulation. Behav. Biol. 13: 369-376.

Bartoshuk, L. M. (1979) Bitter taste of saccharin related to the genetic ability to taste the bitter substance 6-n-propylthiouracil. Science 205: 934-935.

Bereiter, D. A., H. -R. Berthoud, and B. Jeanrenaud (1979) Oropharyngeal hypothalamic input to the same NTS neurons. Soc. Neurosci. Abstr. 5: 125.

Berger, B. D., C. D. Wise, and L. Stein (1973) Area postrema damage and bait-shyness. J. Comp. Physiol. Psychol. 82: 475-479.

Bujas, Z. (1971) Electric taste. In Handbook of Sensory Physiology. Vol. IV: The Chemical Senses 2, Taste, L. M. Beidler, ed., pp. 180-199, Springer-Verlag, Berlin.

Chang, F. -C., and T. R. Scott (1984) A technique for gustatory stimulus delivery in the rodent. Chem. Senses, in press.

Contreras, R. (1977) Changes in gustatory nerve discharges with sodium deficiency: A single unit analysis. Brain Res. 121: 373-378.

Contreras, R., and M. Frank (1979) Sodium deprivation alters neural responses to gustatory stimuli. J. Gen. Physiol. 73: 569-594.

DiLorenzo, P. M., and J. S. Schwartzbaum (1982) Coding of gustatory information in the pontine parabrachial nuclei of the rabbit: Temporal patterns of neural response. Brain Res. 251: 245-257.

Doetsch, G. S., and R. P. Erickson (1970) Synaptic processing of taste-quality information in the nucleus tractus solitarius of the rat. J. Neurophysiol. 33: 490-507. 
Erickson, R. P. (1963) Sensory neural patterns and gustation. In Olfaction and Taste, Y. Zotterman, ed., pp. 205-213, Pergamon Press, Oxford.

Erickson, R. P., G. S. Doetsch, and D. A. Marshall (1965) The gustatory neural response function. J. Gen. Physiol. 49: 247265.

Garcia, J., and F. R. Ervin (1968) Gustatory-visceral and telereceptor-cutaneous conditioning: Adaptation in internal and external milieus. Commun. Behav. Biol. 1: 389-415.

Garcia, J., and W. G. Hankins (1975) The evolution of bitter and the acquisition of toxiphobia. In Olfaction and Taste, D. A. Denton and J. P. Coughlan, eds., Vol. V, pp. 39-45, Academic Press, New York.

Giza, B. K., and T. R. Scott (1983) Blood glucose selectively affects taste-evoked activity in rat nucleus tractus solitarius. Physiol. Behav. 31: 643-650.

Glenn, J. F., and R. P. Erickson (1976) Gastric modulation of gustatory afferent activity. Physiol. Behav. 16: 561-568.

Grill, H. J., and R. Norgren (1978a) The taste reactivity test. I. Mimetic responses to gustatory stimuli in neurologically normal rats. Brain Res. 143: 263-279.

Grill, H. J., and R. Norgren (1978b) The taste reactivity test. II. Mimetic responses to gustatory stimuli in chronic thalamic and chronic decerebrate rats. Brain Res. 143: 281-297.

Grill, H. J., and R. Norgren (1978c) Chronically decerebrate rats demonstrate satiation but not bait shyness. Science 201: 268-269.

Gustavson, C., J. Garcia, W. Hankins, and K. Rusiniak (1974) Coyote predation control by aversive conditioning. Science 184: $581-583$.

Guttman, I. (1968) A general nonmetric technique for finding the smallest coordinate space for a configuration of points. Psychometrika 33: 469-507.

Halpern, B. P., and D. N. Tapper (1971) Taste stimuli: Quality coding time. Science 171: 1256-1258.

Hermann, G. E., and R. C. Rogers (1982) Hepatic and gustatory interactions in the brainstem of rat. Soc. Neurosci. Abstr. 8: 200.

Hodes, R. (1963) Electrocortical synchronization resulting from reduced proprioceptive drive caused by neuromuscular blocking agents. Electroencephalogr. Clin. Neurophysiol. 14: 220232.

Kemble, E. D., and J. A. Nagel (1973) Failure to form a learned taste aversion in rats with amygdaloid lesions. Bull. Psychonom. Soc. 2: 155-156.

Kesner, R. P., R. F. Berman, B. Burton, and W. G. Hankins (1975) Effects of electrical stimulation of amygdala upon neophobia and taste aversion. Behav. Biol. 13: 349-358.

Kolb, B., A. J. Nonneman, and P. Abplanalp (1977) Studies on the neural mechanisms of baitshyness in rats. Bull. Psychonom. Soc. 10: 389-392.

Loullis, C. C., M. J. Wayner, and F. B. Jolicoeur (1978) Thalamic taste nuclei lesions and taste aversion. Physiol. Behav. 20: $653-655$.

McGowan, B. K., W. G. Hankins, and J. Garcia (1972) Limbic lesions and control of the internal and external environment. Behav. Biol. 7: 841-852.

Mikulka, P. J., F. G. Freeman, and P. Lidstrom (1977) The effect of training technique and amygdala lesions on the acquisition and retention of a taste aversion. Behav. Biol. 19: $509-517$.

Miller, I. J., Jr., and K. M. Spangler (1982) Taste bud distribution and innervation on the palate of the rat. Chem. Senses 7: 99-108.

Morrison, G. R. (1967) Behavioral response patterns to salt stimuli in the rat. Can. J. Psychol. 21: 141-152.

Nachman, M. (1962) Taste preferences for sodium salts by adrenalectomized rats. J. Comp. Physiol. Psychol. 55: 1124 1129.

Nachman, M. (1963) Learned aversion to the taste of lithium chloride and generalization to other salts. J. Comp. Physiol. Psychol. 56: 343-349.

Nachman, M., and J. H. Ashe (1974) Effects of basolateral amygdala lesions on neophobia, learned taste aversions, and sodium appetite in rats. J. Comp. Physiol. Psychol. 87: 622643.

Norgren, R. (1976) Taste pathways to hypothalamus and amygdala. J. Comp. Neurol. 166: 17-28.

Norgren, R. (1981) The central organization of the gustatory and visceral afferent systems in the nucleus of the solitary tract. In Brain Mechanisms of Sensation, Y. Katsuki, R. Norgren, and M. Sato, eds., pp. 143-160, John Wiley \& Sons, New York.

Norgren, R., and H. J. Grill (1982) Brainstem control of ingestive behavior. In Physiological Mechanisms of Motivation, D. W. Pfaff, ed., pp. 99-131, Springer-Verlag, Berlin.

Norgren, R., and C. M. Leonard (1973) Ascending central gustatory pathways. J. Comp. Neurol. 150: 217-237.

Outwater, E., and B. Oakley (1981) Inhibition of IX ${ }^{\text {th }}$ nerve taste responses involves cholinergic efferent fibers. Soc. Neurosci. Abstr. 7: 664 .

Pellegrino, L. J., A. S. Pellegrino, and A. J. Cushman (1979) A Stereotaxic Atlas of the Rat Brain, Ed. 2, Plenum Press, New York.

Perrotto, R. S., and T. R. Scott (1976) Gustatory neural coding in the pons. Brain res. 110: 283-300.

Pfaffmann, C. (1978) The vertebrate phylogeny neural code, and integrative processes of taste. In The Handbook of Perception, E. C. Carterette and M. P. Friedman, eds., Vol. VIA, pp. 51-123, Academic Press, New York.

Pfaffmann, C., and T. Pritchard (1980) Ion specificity of "electric taste." In Olfaction and Taste, H. van der Starre, ed., pp. 175-178, IRL Press, London.

Price, J. L., and D. G. Amaral (1981) An autoradiographic study of the projections of the central nucleus of the monkey amygdala. J. Neurosci. 1 : $1242-1259$.

Rabin, B. M., W. A. Hunt, and J. Lee (1983) Attenuation of radiation-labeled and drug-induced conditioned taste aversions following area postrema lesions in the rat. Radiat. Res. 93: 388-394.

Ritter, S., J. J. McGlone, and K. W. Kelley (1980) Absence of lithium-induced taste aversion after area postrema lesion. Brain Res. 201: 501-506.

Roll, D. L., and H. C. Smith (1972) Conditioned taste aversion in anesthetized rats. In Biological Boundaries of Learning, M. E. P. Seligman and J. L. Hager, eds., pp. 98-102, AppletonCentury-Crofts, New York.

Rolls, E. T., and B. J. Rolls (1973) Altered food preferences after lesions in the basolateral region of the amygdala in the rat. J. Comp. Physiol. Psychol. 83: 248-255.

Roth, S. R., M. Schwartz, and P. Teitelbaum (1973) Failure of recovered lateral hypothalamic rats to learn specific food aversions. J. Comp. Physiol. Psychol. 83: 184-197.

Saper, C. B., A. D. Loewy, L. W. Swanson, and W. M. Cowan (1976) Direct hypothalamo-autonomic connections. Brain Res. 177: 305-312.

Schwartz, M., and P. Teitelbaum (1974) Dissociation between learning and remembering in rats with lesions in the lateral hypothalamus. J. Comp. Physiol. Psychol. 87: 384-398.

Scott, T. R. (1974) Behavioral support for a neural taste theory. Physiol. Behav. 12: 113-117.

Scott, T. R., and R. S. Perrotto (1980) Intensity coding in pontine taste area: Gustatory information is processed similarly throughout rat's brainstem. J. Neurophysiol. 44: 739- 
750.

Steiner, J. E. (1973) The human gustofacial response. In The Fourth Symposium on Oral Sensation and Perception, J. F. Bosma, ed., pp. 254-278, United States Department of Health, Education and Welfare, Rockville, MD.
Steiner, J. E. (1974) Discussion paper. Innate discriminative human facial expressions to taste and smell stimulation. Ann. N. Y. Acad. Sci. 237: 229-233.

Wishart, D. (1978) CLUSTAN, Program Library Unit, Edinburgh University, Scotland. 